\title{
Anemia predicts poor outcomes of COVID- 19 in hospitalized patients: a prospective study in Iran
}

\author{
Masood Faghih Dinevari ${ }^{1}$, Mohammad Hossein Somi ${ }^{1}$, Elham Sadeghi Majd ${ }^{2}$, Mahdieh Abbasalizad Farhangi ${ }^{3}$ and \\ Zeinab Nikniaz ${ }^{1 *}$
}

\begin{abstract}
Background: There are limited number of studies with controversial findings regarding the association between anemia at admission and coronavirus disease 2019 (COVID-19) outcomes. Therefore, in this research, we aimed to investigate the prospective association between anemia and COVID-19 outcomes in hospitalized patients in Iran.

Methods: In this prospective study, the data of 1274 consecutive patients hospitalized due to COVID-19 were statistically analyzed. All biomarkers, including hemoglobin and high-sensitivity C-reactive protein (hs-CRP) levels were measured using standard methods. Anemia was defined as a hemoglobin ( $\mathrm{Hb}$ ) concentration of less than 13 $\mathrm{g} / \mathrm{dL}$ and $12 \mathrm{~g} / \mathrm{dL}$ in males and females, respectively. Assessing the association between anemia and COVID-19 survival in hospitalized patients was our primary endpoint.

Results: The mean age of the participants was $64.43 \pm 17.16$ years, out of whom 615 (48.27\%) were anemic subjects. Patients with anemia were significantly older $(P=0.02)$ and had a higher frequency of cardiovascular diseases, hypertension, kidney disease, diabetes, and cancer $(P<0.05)$. The frequency of death (anemic: $23.9 \%$ vs. nonanemic: $13.8 \%$ ), ICU admission (anemic: $27.8 \%$ vs. nonanemic:14.71\%), and ventilator requirement (anemic: $35.93 \%$ vs. nonanemic: $20.63 \%$ ) were significantly higher in anemic patients than in nonanemic patients $(P<0.001)$. According to the results of regression analysis, after adjusting for significant covariate in the univariable model, anemia was independently associated with mortality (OR: 1.68, $95 \%$ Cl: $1.10,2.57, P=0.01$ ), ventilator requirement (OR: 1.74, 95\% Cl: 1.19, 2.54, $P=0.004)$, and the risk of ICU admission (OR: 2.06, 95\% Cl: 1.46, 2.90, $P<0.001)$.
\end{abstract}

Conclusion: The prevalence of anemia in hospitalized patients with COVID-19 was high and was associated with poor outcomes of COVID-19.

Keywords: COVID-19, Anemia, Mortality, Ventilator requirement, ICU admission

\section{Background}

Severe acute respiratory syndrome coronavirus (SARSCOV-2), known as COVID-19, is the new type of coronavirus responsible for the latest pandemic in the world [1]. This virus was initially identified in December 2019

\footnotetext{
* Correspondence: znikniaz@hotmail.com

'Liver and Gastrointestinal Diseases Research Center, Tabriz University of Medical Sciences, Tabriz, Iran

Full list of author information is available at the end of the article
}

in patients with flu-like syndrome and pneumonia in Wuhan, China, and it is rapidly spreading worldwide [1].

COVID-19 is mainly characterized by respiratory symptoms, but it has variable degrees of severity, from mild upper respiratory illness to severe interstitial pneumonia and multiorgan failure leading to death [2]. There are different clinical characteristics and comorbidities associated with severity, hospitalization, and mortality in

C C The Author(s). 2021 Open Access This article is licensed under a Creative Commons Attribution 4.0 International License, which permits use, sharing, adaptation, distribution and reproduction in any medium or format, as long as you give appropriate credit to the original author(s) and the source, provide a link to the Creative Commons licence, and indicate if changes were made. The images or other third party material in this article are included in the article's Creative Commons licence, unless indicated otherwise in a credit line to the material. If material is not included in the article's Creative Commons licence and your intended use is not permitted by statutory regulation or exceeds the permitted use, you will need to obtain permission directly from the copyright holder. To view a copy of this licence, visit http://creativecommons.org/licenses/by/4.0/ The Creative Commons Public Domain Dedication waiver (http://creativecommons.org/publicdomain/zero/1.0/) applies to the data made available in this article, unless otherwise stated in a credit line to the data. 
COVID-19, such as older age, male sex, and severe obesity [3].

There are different laboratory findings upon admission that are early predictors of COVID-19 patients. Patients with severe disease had significantly increased white blood cell (WBC) counts and decreased lymphocyte and platelet counts. Biomarkers of inflammation, cardiac, liver, kidney function, and coagulation markers were also elevated in these patients [4]. In COVID-19 patients, inflammation can lead to an alternation of iron hemostasis and reduced intestinal iron absorption, resulting in the reduced availability of the metal for erythropoiesis and the production of hemoglobin $(\mathrm{Hb})$ [5]. In this regard, some studies focused on the association between anemia and the severity or mortality of COVID-19, the results of which were controversial. Several studies, mostly conducted in China, showed that anemic patients were more likely to have severe disease and higher mortality [5-8]. However, in a study in Italy, Cecconi et al. did not observe any association between anemia and poor outcomes of COVID-19 (8). Similarly, in a study in China, Yang et al. reported no association between low Hb levels and COVID-19 outcomes in hospitalized patients [9].

Currently, COVID-19 is a public health emergency of international concern and there are limited studies with controversial findings regarding the association between anemia at admission and COVID-19 outcomes. Accordingly, in this study, we aimed to investigate the prospective association between anemia and COVID-19 outcomes in hospitalized patients in Tabriz, Iran.

\section{Methods}

In this prospective study, the data of the AzarCoRe (East Azar COVID-19 Registry) were used. In this registry, the patients were registered prospectively based on reverse transcription-polymerase chain reaction (RT-PCR) results or lung imaging features.

The demographic, clinical laboratory, and anthropometric data were collected using questionnaires by trained nurses in all COVID-19-related units. All patients were followed-up until they were discharged from the hospital or death.

All biomarkers, including $\mathrm{Hb}$ and high-sensitivity $\mathrm{C}$ reactive protein (hs-CRP) levels were measured in the laboratory of Imam Reza Hospital of Tabriz, Iran using standard methods.

We registered 1406 patients with COVID-19 in the AzarCoRe. After excluding patients with incomplete information, the data of 1274 patients were statistically analyzed.

\section{Outcomes}

The main obejective of this study was to evaluate the association between anemia and COVID-19 survival in hospitalized patients. In addition, we analyzed the association between anemia and the probability of ICU admission and the requirement of mechanical ventilation at any point.

Anemia was defined according to the World Health Organization (WHO) definition as Hb concentration of less than $13 \mathrm{~g} / \mathrm{dL}$ and $12 \mathrm{~g} / \mathrm{dL}$ in males and females, respectively [10].

Disease severity was defined based on the quick sequential organ failure assessment (qSOFA) score and confusion, urea, respiratory rate, blood pressure, and 65 years of age or older (CURB-65) score. The qSOFA was calculated by summing the scores of the following criteria: Glasgow Coma Scale $<15$, respiratory rate (RR) $\geq 22$, and systolic blood pressure (SBP) $\leq 100$. Curb- 65 was calculated as the sum of the following findings, each of which obtained one point: Glasgow Coma Scale $<15$, blood urea nitrogen $>19 \mathrm{mg} / \mathrm{dL}, \mathrm{RR} \geq 30$, SBP $<90$ $\mathrm{mmHg}$ or diastolic blood pressure (DBP) $\leq 60 \mathrm{mmHg}$, and age $\geq 65$ years. Patients with qSOFA scores $\geq 2$ or CURB-65 scores $\geq 3$ were considered as severe COVID19 cases [11, 12].

\section{Statistical analysis}

For statistical analysis, SPSS version 25.0 (IBM Corporation, NY, USA) was used. The normality of the data distribution was analyzed by the Kolmogorov-Smirnov test. The quantitative and qualitative values were reported as the mean (SD) and frequency (\%), respectively. Between-group comparisons were performed using the independent $\mathrm{t}$-test for continuous variables and the chisquare test for categorical variables. Logistic regression was used to analyze the association between anemia and COVID-19 outcomes in univariable and multivariable models. Factors that had a significant association in the univariable model were considered in the multivariable model. For all analyses, a $P$-value $<0.05$ was considered significant.

\section{Results}

In the present study, 1274 COVID-19 patients with a mean age of $64.43 \pm 17.16$ years were included, out of whom 615 (48.27\%) were anemic. There was a significant association between sex and anemia $(P=0.03)$. As shown in Table 1, patients with anemia were significantly older $(P=0.02)$ and had a higher frequency of cardiovascular diseases $(P=0.03)$, hypertension $(P<0.001)$, kidney diseases $(P<0.001)$, diabetes $(P<0.001)$, and cancer $(P<$ $0.001)$. Moreover, there was a significant association between body mass index $(\mathrm{BMI})$ and anemia $(P=0.02)$.

The frequency of COVID-19 outcomes stratified by anemia status is shown in Fig. 1. The frequency of death, ICU admission, and ventilator requirement were 
Table 1 The demographic characteristics of patients with COVID-19

\begin{tabular}{|c|c|c|c|c|}
\hline Demographic variables & Total $(n=1274)$ & No-Anemia $(n=659)$ & $\begin{array}{l}\text { Anemia } \\
(n=615)\end{array}$ & $p$-value \\
\hline Age (years) Mean \pm SD & $64.43 \pm 17.16$ & $62.39 \pm 17.15$ & $64.53 \pm 17.12$ & 0.02 \\
\hline \multicolumn{5}{|l|}{ Sex, } \\
\hline Males n (\%) & $706(55.41)$ & $384(58.27)$ & $322(52.35)$ & \multirow[t]{2}{*}{0.03} \\
\hline Females n (\%) & $568(44.59)$ & $275(41.73)$ & $293(47.65)$ & \\
\hline Smoking n (\%) & $74(5.80)$ & $40(6.06)$ & $34(5.52)$ & 0.74 \\
\hline \multicolumn{5}{|l|}{ Comorbidities n (\%) } \\
\hline CVD & $435(34.14)$ & $138(20.94)$ & $297(48.29)$ & 0.03 \\
\hline Respiratory diseases & $171(13.42)$ & $89(13.50)$ & $82(13.33)$ & 0.9 \\
\hline HTN & $504(39.56)$ & $244(37.02)$ & $260(42.27)$ & 0.03 \\
\hline Kidney diseases & $112(8.79)$ & $26(3.94)$ & 86 (13.98) & $<0.001$ \\
\hline Diabetes & $288(22.60)$ & $121(18.36)$ & $167(27.15)$ & $<0.001$ \\
\hline Carcinoma & $59(4.63)$ & $11(1.66)$ & $48(7.80)$ & $<0.001$ \\
\hline Liver diseases & $24(1.88)$ & $13(1.97)$ & $11(1.78)$ & 0.85 \\
\hline Autoimmune diseases & $14(1.09)$ & $4(0.6)$ & $10(1.62)$ & 0.07 \\
\hline BMI categories n (\%) & & & & 0.02 \\
\hline Underweight $\left(\mathrm{BMI}<18.5 \mathrm{~kg} / \mathrm{m}^{2}\right)$ & $420(32.96)$ & $196(29.7)$ & $224(36.4)$ & \\
\hline Normal weight (BMI: $18.5-25$ kg/m²) & $528(41.44)$ & $287(43.5)$ & $241(39.1)$ & \\
\hline Overweight/Obese $\left(\mathrm{BMI}>25 \mathrm{~kg} / \mathrm{m}^{2}\right)$ & $326(25.5)$ & $176(26.7)$ & $150(24.3)$ & \\
\hline hs-CRP (mg/l) & $4.01 \pm 8.61$ & $4.15 \pm 9.77$ & $3.85 \pm 7.29$ & 0.84 \\
\hline Severe disease $\mathrm{n}(\%)$ & $67(5.25)$ & $23(3.49)$ & $38(6.17)$ & 0.01 \\
\hline Temperature $\left({ }^{\circ} \mathrm{C}\right)$ & $36.83 \pm 4.13$ & $36.92 \pm 3.55$ & $36.67 \pm 4.91$ & 0.54 \\
\hline Hypoxia n (\%) & $466(36.57)$ & $242(36.72)$ & $224(36.42)$ & 0.81 \\
\hline
\end{tabular}

CVD Cardiovascular disease, HTN Hypertension, BMI Body mass index, $h s-C R P$ high sensitive C-Reactive protein ${ }^{*} p$-value of independent t-test

${ }^{* *} p$-value of chi-square test

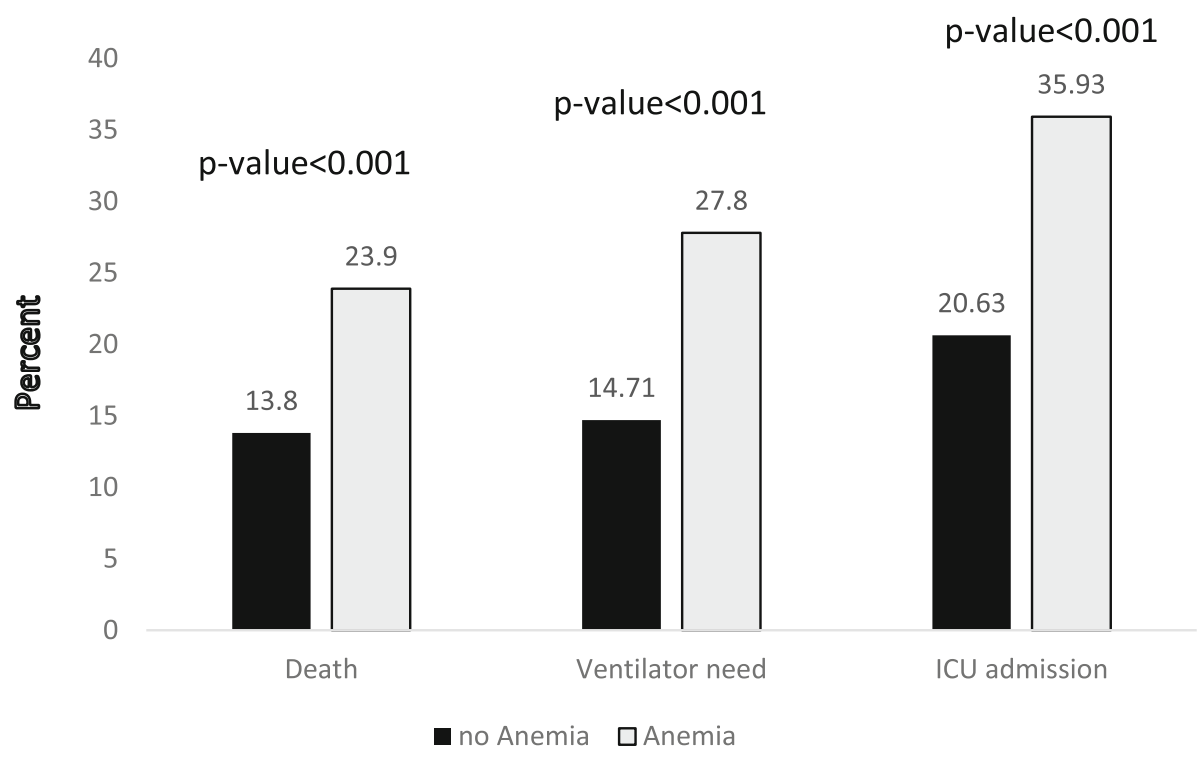

Fig. 1 The frequency of outcomes of COVID-19 stratified by anemia status 
significantly higher in anemic patients than in nonanemic ones $(P<0.001)$.

Table 2 depicts the association between anemia (independent factor) and COVID-19 mortality in univariable and multivariable models. In the multivariable model, after adjusting for variables with significant associations in the univariable model such as age, hypoxia, respiratory diseases, diabetes, smoking status, and diseases severity, an independent significant association was observed between anemia (OR: 1.68, 95\% CI: 1.10, 2.57, $P=0.01)$ and COVID-19 mortality.

The association between anemia and ventilator requirement in hospitalized patients with COVID-19 is shown in Table 3. After adjusting for variables that had a significant association with ventilator requirement in the univariable model such as age, hypoxia, respiratory diseases, diseases severity, it was verified that anemia was an independent and significant risk factor for ventilator requirement (OR: 1.74, 95\% CI: 1.19, 2.54, $P=0.004$ ).

As shown in Table 4, in hospitalized patients with COVID-19, after adjusting for sex, hypoxia, smoking status, and disease severity, anemia was an independent and significant risk factor for ICU admission (OR: 2.06, 95\% CI: 1.46, 2.90, $P<0.001)$.

\section{Discussion}

COVID-19 is an infectious disease with a high mortality rate. In this regard, different studies have attempted to investigate the factors associated with poor outcomes in these patients. Accordingly, in the present study, we assessed the association between anemia status on admission and COVID-19 outcomes. Our results showed that the prevalence of anemia was high (48\%) in hospitalized COVID-19 patients. However, Bellmann-Weiller reported that $24.7 \%$ of patients with COVID-19 on admission were anemic in Austria [5]. The higher prevalence of anemia in our study may be related to a higher prevalence of pre-existing anemia in Iran, a higher percentage of the female population in our study, and differences in comorbidities, anemia definition used in different studies, and disease severity.

In addition, our results showed that anemic patients were significantly more likely to develop poor outcomes of COVID-19, including death, ventilator need, and ICU admission. This finding is in line with the results of previous studies that reported a significantly lower level of $\mathrm{Hb}$ in patients with severe COVID-19 disease [5-8, 13]. In other pulmonary diseases, anemia was shown to be a risk factor for increased duration of hospitalization and hospital admission [14]. However, Yang et al. [9] and

Table 2 The logistic regression analysis of anemia and death during hospitalization in patients with COVID-19

\begin{tabular}{|c|c|c|c|c|c|c|}
\hline \multirow[t]{2}{*}{ Variables } & \multicolumn{3}{|c|}{ Univariate model } & \multicolumn{3}{|c|}{ Multivariate model $^{\mathrm{a}}$} \\
\hline & Odds Ratio & $\mathrm{Cl}$ & $P$-value & Odds Ratio & $\mathrm{Cl}$ & $P$-value \\
\hline Age & 1.02 & $1.01,1.03$ & $<0.001$ & 1.03 & $1.01,1.04$ & $<0.001$ \\
\hline Sex & 0.82 & $0.62,1.09$ & 0.17 & & & \\
\hline BMI & 1.00 & $0.97,1.03$ & 0.98 & & & \\
\hline Temperature & 0.99 & $0.97,1.02$ & 0.74 & & & \\
\hline Hypoxia & 3.30 & $2.45,4.46$ & $<0.001$ & 2.30 & $1.51,3.50$ & $<0.001$ \\
\hline CVD & 1.27 & $0.92,1.76$ & 0.13 & & & \\
\hline Respiratory diseases & 1.51 & $1.02,2.24$ & 0.03 & 1.07 & $0.61,1.87$ & 0.80 \\
\hline HTN & 1.18 & $0.88,1.58$ & 0.24 & & & \\
\hline Kidney diseases & 1.27 & $0.80,2.01$ & 0.30 & & & \\
\hline Cancers & 1.24 & $0.66,2.34$ & 0.49 & & & \\
\hline Autoimmune diseases & 3.16 & $0.04,2.41$ & 0.26 & & & \\
\hline Diabetes & 1.60 & $1.16,2.19$ & 0.004 & 1.52 & $0.96,2.41$ & 0.07 \\
\hline Liver diseases & 0.20 & $0.02,1.52$ & 0.12 & & & \\
\hline Smoking & 2.00 & $1.18,3.40$ & 0.01 & 1.76 & $0.88,3.58$ & 0.11 \\
\hline Disease severity & 2.45 & $1.38,4.34$ & 0.002 & 2.03 & $0.96,2.41$ & 0.06 \\
\hline hs-CRP level & 0.96 & $0.9,1.01$ & 0.80 & & & \\
\hline Anemia & 2.01 & $1.50,2.69$ & $<0.001$ & 1.68 & $1.10,2.57$ & $0.01^{* *}$ \\
\hline
\end{tabular}

Dependent variable: Death

CVD cardiovascular disease, HTN Hypertension, BMI Body mass index, CRP C-Reactive protein, $h s$-CRP high sensitive-C reactive protein

${ }^{a}$ Multivariate model adjusted for all variables with significant association in Univariate model

**adjusted for age, hypoxia, respiratory diseases, diabetes, smoking status, diseases severity 
Table 3 The logistic regression analysis of anemia and mechanical ventilator requirement during hospitalization in patients with COVID-19

\begin{tabular}{|c|c|c|c|c|c|c|}
\hline \multirow[t]{2}{*}{ Variables } & \multicolumn{3}{|c|}{ Univariate model } & \multicolumn{3}{|c|}{ Multivariate model $^{\mathrm{a}}$} \\
\hline & Odds Ratio & $\mathrm{Cl}$ & $P$-value & Odds Ratio & $\mathrm{Cl}$ & $P$-value \\
\hline Age & 1.01 & $1.00,1.02$ & 0.001 & 1.01 & $1.00,1.02$ & 0.005 \\
\hline Sex & 0.78 & $1.00,1.02$ & 0.08 & & & \\
\hline BMI & 0.99 & $0.96,1.02$ & 0.89 & & & \\
\hline Temperature & 0.97 & $0.93,1.01$ & 0.26 & & & \\
\hline Hypoxia & 4.12 & $3.06,5.56$ & $<0.001$ & 3.47 & $2.37,5.07$ & $<0.001$ \\
\hline CVD & 1.35 & $0.99,1.85$ & 0.05 & & & \\
\hline Respiratory Diseases & 1.59 & $1.09,2.32$ & $<0.001$ & 1.45 & $0.90,2.34$ & 0.11 \\
\hline HTN & 1.25 & $0.95,1.66$ & 0.10 & & & \\
\hline Kidney diseases & 1.14 & $0.72,1.81$ & 0.56 & & & \\
\hline Cancers & 1.45 & $0.80,2.62$ & 0.21 & & & \\
\hline Autoimmune diseases & 0.32 & $0.03,2.31$ & 0.25 & & & \\
\hline Diabetes & 1.22 & $0.89,1.67$ & 0.21 & & & \\
\hline Liver diseases & 0.35 & $0.08,1.52$ & 0.16 & & & \\
\hline Smoking & 1.44 & $0.81,2.55$ & 0.20 & & & \\
\hline Disease severity & 3.61 & $2.09,6.24$ & $<0.001$ & 2.73 & $1.48,5.03$ & $<0.001$ \\
\hline CRP level & 0.99 & $0.98,1.01$ & 0.89 & & & \\
\hline Anemia & 2.12 & $1.60,2.81$ & $<0.001$ & 1.74 & $1.19,2.54$ & $0.004^{* *}$ \\
\hline
\end{tabular}

Dependent variable: requirement for mechanical ventilation

CVD cardiovascular disease, HTN Hypertension, BMI Body mass index, CRP C-Reactive protein

${ }^{a}$ Multivariate model was adjusted for all variables with significant association in Univariate model

${ }^{* *}$ Adjusted for age, hypoxia, respiratory diseases, diseases severity, and Anemia

Table 4 The logistic regression analysis of anemia and ICU admission during hospitalization in patients with COVID-19

\begin{tabular}{|c|c|c|c|c|c|c|}
\hline \multirow[t]{2}{*}{ Variables } & \multicolumn{3}{|c|}{ Univariate model } & \multicolumn{3}{|c|}{ Multivariate model $^{\mathrm{a}}$} \\
\hline & Odds Ratio & $\mathrm{Cl}$ & $P$-value & Odds Ratio & $\mathrm{Cl}$ & $P$-value \\
\hline Age & 1.00 & $0.99,1.01$ & 0.15 & & & \\
\hline Sex & 0.73 & $0.57,0.94$ & 0.01 & 0.66 & $0.46,0.93$ & 0.02 \\
\hline BMI & 0.99 & $0.97,1.02$ & 0.83 & & & \\
\hline Temperature & 0.97 & $0.93,1.01$ & 0.21 & & & \\
\hline Hypoxia & 3.04 & $2.34,3.96$ & $<0.001$ & 2.57 & $1.84,3.60$ & $<0.001$ \\
\hline CVD & 1.26 & $0.95,1.68$ & 0.1 & & & \\
\hline Respiratory diseases & 1.40 & $0.98,1.99$ & 0.05 & & & \\
\hline HTN & 1.04 & $0.81,1.35$ & 0.72 & & & \\
\hline Kidney diseases & 1.10 & $0.72,1.66$ & 0.65 & & & \\
\hline Cancers & 1.46 & $0.84,2.54$ & 0.17 & & & \\
\hline Autoimmune diseases & 0.47 & $0.10,2.14$ & 0.33 & & & \\
\hline Diabetes & 1.16 & $0.87,1.55$ & 0.30 & & & \\
\hline Liver diseases & 0.51 & $0.17,1.51$ & 0.22 & & & \\
\hline Smoking & 1.67 & $1.01,2.76$ & 0.04 & 1.06 & $0.54,2.08$ & 0.85 \\
\hline Disease severity & 2.43 & $1.41,4.17$ & 0.001 & 1.90 & $1.02,3.52$ & 0.04 \\
\hline CRP level & 0.99 & $0.97,1.01$ & 0.47 & & & \\
\hline Anemia & 2.02 & $1.58,2.63$ & $<0.001$ & 2.06 & $1.46,2.90$ & $<0.001^{* *}$ \\
\hline
\end{tabular}

Dependent variable: ICU admission

CVD cardiovascular disease, HTN Hypertension, BMI Body mass index, CRP C-Reactive protein

aultivariate model adjusted for all variables with significant association in Univariate model

**adjusted for sex, hypoxia, smoking status, diseases severity, and Anemia 
Cecconi et al. [3] did not report a significant association between low Hb levels and COVID-19 survival. The observed discrepancy may be related to the design of the study (retrospective vs. prospective), sample size, and inclusion criteria.

The association between anemia and poor outcomes in unadjusted models may be partly related to higher age and higher prevalence of some comorbidities in anemic patients [15]. However, we also observed a significant association after accounting for the disease severity, presence of comorbidities, age, sex, and hypoxia status. This may be partly due to the effect of anemia on immunity, which in turn increases the probability of poor outcomes in patients with COVID-19 [16]. Furthermore, anemia activates the sympathetic nervous system, which increases heart rate, blood pressure, and pulmonary capillary leakage, causing acute respiratory distress syndrome (ARDS) [17].

The present study had some limitations. First, we defined anemia based on the levels of $\mathrm{Hb}$ on admission, and we had no information on the $\mathrm{Hb}$ levels before infection and $\mathrm{dy}-$ namic $\mathrm{Hb}$ levels during hospitalization. Second, we did not measure other biomarkers of anemia, including serum iron, ferritin, and transferrin levels. Third, we included all patients in Imam Reza Hospital of Tabriz as a provincial and regional referral center for COVID-19, which might limit the generalizability of results.

The strengths of this study include the prospective nature of the study, including the large sample of patients with COVID-19, and considering a large number of confounding factors that may affect the association between anemia and COVID-19 outcomes.

\section{Conclusions}

The results of the present study showed that the prevalence of anemia in hospitalized patients with COVID-19 was high, and it was associated with poor outcomes of COVID-19. From a practical point of view, the Hb level should be closely monitored during illness and hospitalization. However, further studies are required to confirm whether the $\mathrm{Hb}$ level can be used as a prognostic marker.

\footnotetext{
Abbreviations

ARDS: Acute respiratory distress syndrome; BMI: Body mass index; COVID19: Coronavirus disease 2019; Curb-65: Confusion, urea, respiratory rate, blood pressure, and 65 years of age or older; DBP: Diastolic blood pressure; Hb: Hemoglobin; hs-CRP: High-sensitivity C-reactive protein; ICU: Intesive care unit; OR: Odds ratio; qSOFA: Quick sequential organ failure assessment; RR: Respiratory rate; RT-PCR: Reverse transcription-polymerase chain reaction; SARS-COV-2: Severe acute respiratory syndrome coronavirus; SBP: Systolic blood pressure; SD: Standard deviation; SPSS: Statistical package for social sciences; WBC: White blood cell; WHO: World health organization
}

\section{Acknowledgments}

The authors wish to thank the Liver and Gastrointestinal Diseases Research Center, East Azar COVID-19 Registry, and all nurses and staff of Imam Reza Hospital, Tabriz University of Medical Sciences for their collaboration.

\section{Authors' contributions}

Conception and design: MHS, ZN, MFD; acquisition of data: ESM, ZN; data analysis: MAF, ZN; Data interpretation: ZN, MFD, MHS; drafting the manuscript: ZN, MAF; revising manuscript critically: ZN, MHS, MFD, ESM; given final approval of the version to be published: MFD, MHS, ESM, ZN, MAF; Agreed to be accountable for all aspects of the work: ZN, ESM, MFD, MHS, MAF. The author(s) read and approved the final manuscript.

\section{Funding}

This study was funded by the Liver and Gastrointestinal Diseases Research Center, Tabriz University of Medical Sciences, Tabriz, Iran. The funder had no role in the study design, data collection, analysis, decision to publish, or preparation of the manuscript.

\section{Availability of data and materials}

The datasets generated and/or analyzed during the current study are not publicly available due to the institution's policy, but are available from the corresponding author upon reasonable request.

\section{Ethics approval and consent to participate}

The research ethics committee of Tabriz University of Medical Sciences, Iran approved the study (code: IR.TBZMED.REC.1398.1274) and a written informed consent was obtained from all patients.

\section{Consent for publication}

Not applicable.

\section{Competing interests}

The authors declare no conflict of interests.

\section{Author details}

'Liver and Gastrointestinal Diseases Research Center, Tabriz University of Medical Sciences, Tabriz, Iran. ${ }^{2}$ Student Research Committee, Tabriz University of Medical Sciences, Tabriz, Iran. ${ }^{3}$ Community Nutrition Department, Tabriz University of Medical Sciences, Tabriz, Iran.

Received: 22 August 2020 Accepted: 3 February 2021

Published online: 10 February 2021

References

1. Raoult D, Zumla A, Locatelli F, Ippolito G, Kroemer G. Coronavirus infections: epidemiological, clinical and immunological features and hypotheses. Cell Stress. 2020;4(4):66.

2. Madabhavi I, Sarkar M, Kadakol N. COVID-19: a review. Monaldi Arch Chest Dis. 2020;90(2):248-58.

3. Cecconi M, Piovani D, Brunetta E, Aghemo A, Greco M, Ciccarelli M, Angelini C, Voza A, Omodei P, Vespa E. Early predictors of clinical deterioration in a cohort of 239 patients hospitalized for Covid-19 infection in Lombardy, Italy. J Clin Med. 2020;9(5):1548.

4. Henry BM, De Oliveira MHS, Benoit S, Plebani M, Lippi G. Hematologic, biochemical and immune biomarker abnormalities associated with severe illness and mortality in coronavirus disease 2019 (COVID-19): a metaanalysis. Clin Chem Lab Med (CCLM). 2020;58(7):1021-8.

5. Bellmann-Weiler R, Lanser L, Barket R, Rangger L, Schapfl A, Schaber M, Fritsche G, Wöll E, Weiss G. Prevalence and predictive value of Anemia and Dysregulated Iron homeostasis in patients with COVID-19 infection. J Clin Med. 2020;9(8):2429.

6. Guan W-j, Ni Z-y, Hu Y, Liang W-h, Ou C-q, He J-x, Liu L, Shan H, Lei C-I, Hui DS. Clinical characteristics of coronavirus disease 2019 in China. N Engl J Med. 2020;382(18):1708-20.

7. Tao Z, Liu M, Wu J, Xu J, Chen W, Yang Z, Xu X, Liu L, Chen R, Xie J. Anaemia is associated with severe illness in COVID-19: a retrospective cohort study; 2020.

8. Young B, Ong S, Kalimuddin S, Low J, Tan S, Loh J, Ng O, Marimuthu K, Ang L, Mak T. Singapore Novel Coronavirus Outbreak Research T. Epidemiologic Features and Clinical Course of Patients Infected With SARS-CoV-2 in Singapore. JAMA. 2020;323(15):1488-94.

9. Yang X, Yu Y, Xu J, Shu H, Liu H, Wu Y, Zhang L, Yu Z, Fang M, Yu T. Clinical course and outcomes of critically ill patients with SARS-CoV-2 pneumonia in Wuhan, China: a single-centered, retrospective, observational study. Lancet Respir Med. 2020;8(5):475-81. 
10. McLean E, Cogswell M, Egli I, Wojdyla D, De Benoist B. Worldwide prevalence of anaemia, WHO vitamin and mineral nutrition information system, 1993-2005. Public Health Nutr. 2009;12(4):444-54.

11. Chang CL, Sullivan GD, Karalus NC, Mills GD, Mclachlan JD, Hancox RJ. Predicting early mortality in acute exacerbation of chronic obstructive pulmonary disease using the CURB65 score. Respirology. 2011;16(1):146-51.

12. Seymour CW, Liu VX, Iwashyna TJ, Brunkhorst FM, Rea TD, Scherag A, Rubenfeld G, Kahn JM, Shankar-Hari M, Singer M. Assessment of clinical criteria for sepsis: for the third international consensus definitions for Sepsis and septic shock (Sepsis-3). Jama. 2016;315(8):762-74.

13. Huang C, Wang Y, Li X, Ren L, Zhao J, Hu Y, Zhang L, Fan G, Xu J, Gu X. Clinical features of patients infected with 2019 novel coronavirus in Wuhan, China. Lancet. 2020;395(10223):497-506.

14. Nguyen HQ, Chu L, Amy Liu I-L, Lee JS, Suh D, Korotzer B, Yuen G, Desai S, Coleman KJ, Xiang AH. Associations between physical activity and 30-day readmission risk in chronic obstructive pulmonary disease. Ann Am Thorac Soc. 2014;11(5):695-705.

15. Zhou F, Yu T, Du R, Fan G, Liu Y, Liu Z, Xiang J, Wang Y, Song B, Gu X. Clinical course and risk factors for mortality of adult inpatients with COVID19 in Wuhan, China: a retrospective cohort study. Lancet. 2020.

16. Ryan AS. Iron-deficiency anemia in infant development: implications for growth, cognitive development, resistance to infection, and iron supplementation. Am J Phys Anthropol. 1997;104(S25):25-62.

17. Cure E, Cure MC. Angiotensin-converting enzyme inhibitors and angiotensin receptor blockers may be harmful in patients with diabetes during COVID19 pandemic. Diabetes Metab Synd. 2020

\section{Publisher's Note}

Springer Nature remains neutral with regard to jurisdictional claims in published maps and institutional affiliations.

Ready to submit your research? Choose BMC and benefit from:

- fast, convenient online submission

- thorough peer review by experienced researchers in your field

- rapid publication on acceptance

- support for research data, including large and complex data types

- gold Open Access which fosters wider collaboration and increased citations

- maximum visibility for your research: over $100 \mathrm{M}$ website views per year

At $\mathrm{BMC}$, research is always in progress.

Learn more biomedcentral.com/submissions 